\title{
FLOW RATE CONTROL OF VARIABLE DISPLACEMENT PISTON PUMP WITH PRESSURE COMPENSATION USING NEURAL NETWORK
}

\section{Ayman A. Aly}

Assistant Prof., Mechatronics Section, Mech. Eng. Dept., Assiut University, Assiut, 7156, Egypt E-mail: ayman_aly@yahoo.com

\section{(Received June 28, 2007, Accepted September 9, 2007)}

One of the most important components in hydraulic circuits is the pump that generates hydraulic power supply. The performance and the versatility of a variable displacement piston pump are, to a large extent, determined by its controller. Upgrading of existing controllers is considered one of the major means of improving the characteristics of the pump. The dynamic performance of hydraulic systems with a demand flow supply not only depends on the performance of the flow modulation valve, but also on the performance of the pump. In this study, the performance of soft computing methodology, trained Neural Network (NN) based on the conventional PID controller, is used for the control of a swash plate displacement while the compensation of the effect of the back up pressure is implemented by inverse NN model. The feasibility of system is simulated and issue of implementation such pumps control is established. It is seen that the use of the proposed methodology results in some desirable characteristics.

KEYEORDS: Flow Rate Control, Neural Network, Variable Displacement Axial Piston Pump, Inverse Model.

\section{Nomenclature}

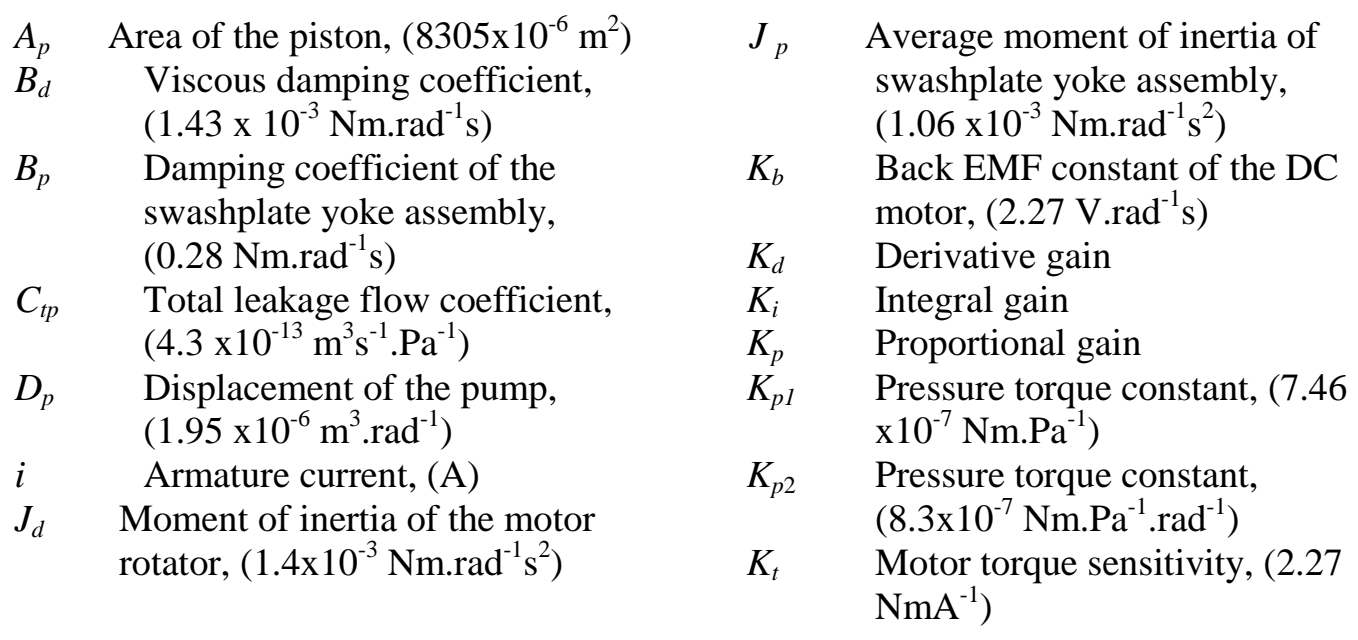




\begin{tabular}{|c|c|c|c|}
\hline$L$ & $\begin{array}{l}\text { Terminal inductance of the DC } \\
\text { motor windings, }(0.0332 \mathrm{H}) \\
\text { Number of pistons, }(9 \text { pistons })\end{array}$ & $\begin{array}{l}T_{d s} \\
T_{e}\end{array}$ & $\begin{array}{l}\text { Static friction torque, }(\mathrm{Nm}) \\
\text { Motor electrical time constant, } \\
\left(6.87 \times 10^{-3} \mathrm{sec}\right)\end{array}$ \\
\hline$P_{p}$ & Pump pressure, $(\mathrm{Pa})$ & $T_{f c}$ & Torque produced by the \\
\hline$Q_{e p}$ & $\begin{array}{l}\text { External leakage flow of the } \\
\text { pump, }\left(\mathrm{m}^{3} \mathrm{~s}^{-1}\right)\end{array}$ & & $\begin{array}{l}\text { coulomb friction force, }(0.36 \\
\mathrm{Nm})\end{array}$ \\
\hline$Q_{i p}$ & $\begin{array}{l}\text { Internal leakage flow of the } \\
\text { pump, }\left(\mathrm{m}^{3} \mathrm{~s}^{-1}\right)\end{array}$ & $T_{m}$ & $\begin{array}{l}\text { Motor mechanical time } \\
\text { constant, }\left(1.3 \times 10^{-3} \mathrm{sec}\right)\end{array}$ \\
\hline$Q_{p}$ & Output flow of the pump, $\left(\mathrm{m}^{3} \mathrm{~s}^{-1}\right)$ & $V$ & Input voltage, $(\mathrm{V})$ \\
\hline$R$ & Terminal resistance of the DC & $V_{e m f}$ & back EMF voltage, $(\mathrm{V})$ \\
\hline & motor windings, $(4.83 \Omega)$ & $V_{p}$ & $\begin{array}{l}\text { Volume of the pump forward } \\
\text { chamber, }\left(3 \times 10^{-5} \mathrm{~m}^{3}\right)\end{array}$ \\
\hline $\boldsymbol{\kappa}_{p}$ & $\begin{array}{l}\text { Radius of the piston pitch, } \\
(0.0224 \mathrm{~m})\end{array}$ & $\beta_{\mathrm{e}}$ & Bulk modulus of the fluid, \\
\hline$S_{1}$ & Simplified pump model & & $\left(1.45 \times 10^{9} \mathrm{~Pa}\right)$ \\
\hline & constant, $(0.096 \mathrm{Nm})$ & $\theta_{p}$ & Angular position of the DC \\
\hline$S_{2}$ & $\begin{array}{l}\text { Simplified pump model } \\
\text { constant, }\left(2.36 \mathrm{Nm} \cdot \mathrm{rad}^{-1}\right)\end{array}$ & & $\begin{array}{l}\text { motor shaft and pump } \\
\text { swashplate, }(\mathrm{rad})\end{array}$ \\
\hline$T_{d}$ & $\begin{array}{l}\text { Torque applied to the yoke by } \\
\text { the DC motor, }(\mathrm{Nm})\end{array}$ & $\omega_{\mathrm{p}}$ & $\begin{array}{l}\text { Pump rotational speed, (183.3 } \\
\left.\operatorname{rad~s}^{-1}\right)\end{array}$ \\
\hline$T_{d c}$ & Coulomb friction torque, $(\mathrm{Nm})$ & $\gamma$ & Damping factor. \\
\hline$T_{d l}$ & $\begin{array}{l}\text { Load torque acting on the DC } \\
\text { motor shaft, }(\mathrm{Nm})\end{array}$ & & \\
\hline
\end{tabular}

\section{INTRODUCTION}

Variable displacement piston pumps have found widespread application in the field of fluid power industry. The most common way to vary the flow rate of a pump is to vary its "displacement" or "piston stroke" when it is operated under a constant rotational speed. A variable displacement pump is designed such that the displacement can be varied from zero to some maximum value while the pump is operating. The variable displacement axial piston pump which is shown in Fig.1 has many applications in fluid power systems. Changing the angle of the swashplate can change the piston stroke. Since the displacement of the pump is proportional to the piston stroke, the displacement can be changed by varying the angle of the swashplate, [1].

A DC motor is directly coupled to the pintle of the swashplate as shown in Fig. 2. It is anticipated that a DC motor should provide a rapid dynamic response to the pump swashplate. The reason for this anticipation is that the maximum torque provided by the DC motor is about $60 \mathrm{Nm}$ [2], which is much higher than the torque generated by its hydraulic counterpart (13 Nm to fully destroke the pump). Then, the dynamic response of the pump flow rate should be increased. Further, it is much easier to integrate a DC motor to an electronic feedback circuit. This design strategy enables sophisticated electronic control algorithms to be applied for the DC motor controller.

Since a DC motor can initially locate the swashplate at any angular position, even at zero position, it is much easier to control the initial flow rate of the pump and to build the system pressure using this design. Because there is no return spring in the pump, 
the torque generated by the DC motor is mainly used to overcome the friction torque and the "back" torque [3] produced by the pump pressure.

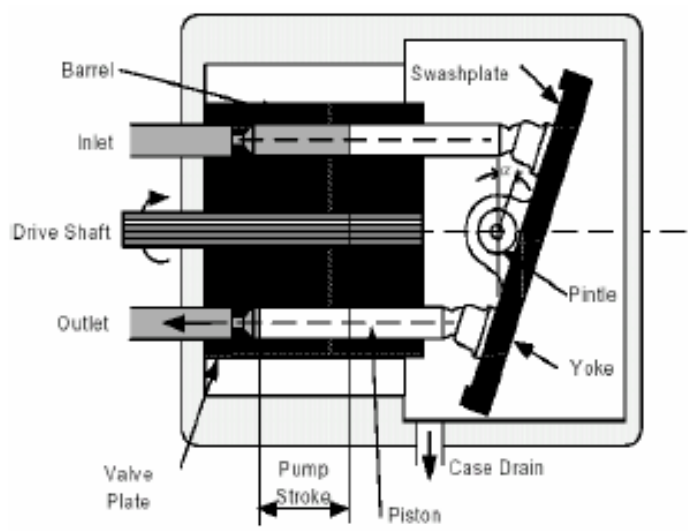

Fig.1 Schematic of variable displacement piston pump

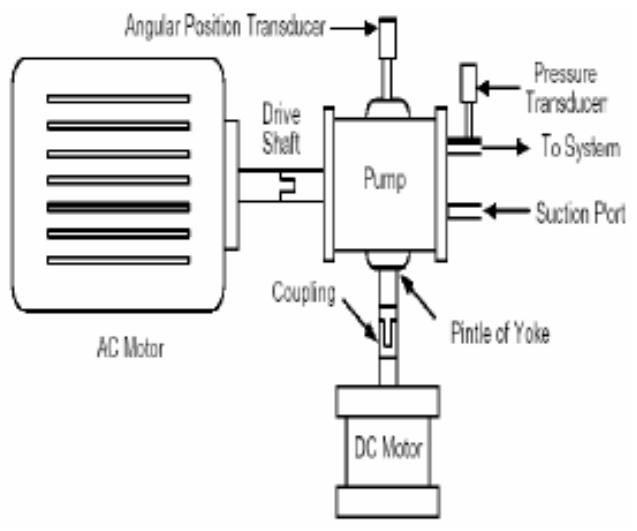

Fig.2 Direct swashplate control with a DC motor

Several investigators $[4,5]$ have applied research about the dynamic properties of a variable displacement piston pump. Most of these investigations are based on a linearized model of the pump dynamics. In industrial application, the dynamic characteristics of the variable delivery pump are always complex and highly nonlinear, [6]. Moreover, there are too many uncertainties in it; as the viscosity of the oil, the bulk modulus, leakage coefficient, equivalent torque coefficient, volumetric displacement and others. So, the design of such pumps control flow at different pump pressure levels needs various controllers that cause the pump output to match different load characteristics more efficiently and effectively. The design of these controllers, however, is often based on compromise and thus their performances are very operating condition dependent.

Neural Network $(\mathrm{NN})$ methods have become very popular recently involving mapping of input-output vectors for cases where no theoretical model works satisfactorily. An artificial NN [7-9] is an information-processing paradigm inspired by the manner in which the heavily interconnected, parallel structure of the human brain processes information. They are collections of mathematical processing units that emulate some of the observed properties of biological nervous systems and draw on the analogies of adaptive biological learning. NNs are trainable systems whose learning abilities, tolerance to uncertainty and noise, and generalization capabilities are derived from their distributed network structure and knowledge representation. Learning of a $\mathrm{NN}$ typically implies adjustments of connection weights and biases so that the square error (between NN output and desired output) is minimized. In this study a NN controller technique is examined as applied to control the pump flow rate and compensate its back pressure effect. 


\section{MATHEMATICAL MODEL OF THE DC MOTOR CONTROLLED PUMP}

One approach to model a dynamic system is to use linear or small signal analysis. The linear analysis method is based on the assumption that a linear transfer function can be used to describe the behavior of the plant over the complete operating range. On the other hand, the small signal analysis method assumes that the plant behavior is nonlinear but the model can be linearized over a small range near an operating point. Both methods are very powerful analytical tools but have limitations, especially for a highly nonlinear dynamic system such as the DC motor controlled pump. In this study, the pump is modeled using nonlinear large signal techniques which are represented by a series of differential equations. Although it is difficult to analyze the dynamic performance of a nonlinear model using conventional control theories (transfer function approaches), it is feasible to do this using a simulation program.

The flow rate is determined by the angle of the swashplate which, is controlled using a permanent magnet servo DC motor, [2]. From the viewpoint of the pump control, the DC motor can be considered as a part of the pump. Hence, the model of the DC motor is also a part of the pump model.

The mathematic model of a DC motor can be derived using a schematic diagram of the motor circuit shown in Fig.3. The DC motor is assumed to consist of inertia, $J_{d}$, with damping, $B_{d}$. The torque developed by the current in motor windings not only overcomes the friction in the DC motor and load torque, $T_{d l}$, on the motor shaft but also accelerates the rotor, [10].

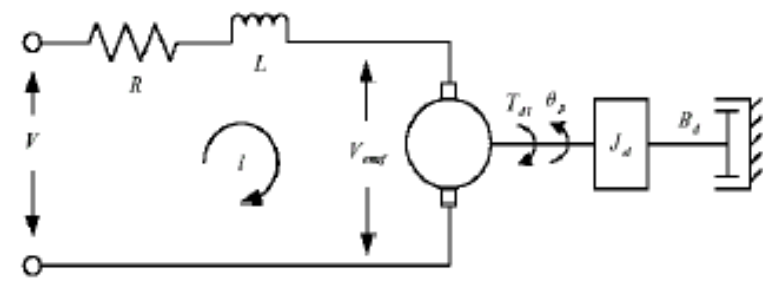

Fig.3. Schematic diagram of a DC motor

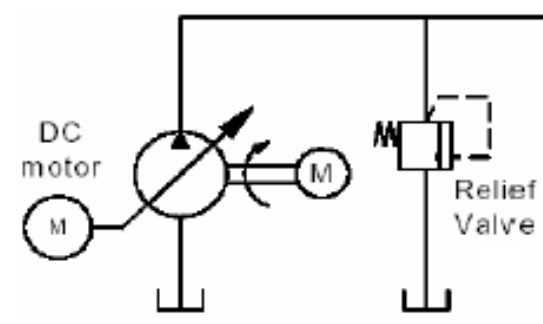

Fig.4 Pump-controlled system with Relief Valve

The electrical circuit of the motor can be simply described by:

$$
\begin{aligned}
& V=V_{e m f}+R i+L \frac{d i}{d t} \\
& V_{e m f}=K_{b} \dot{\theta_{p}}
\end{aligned}
$$

The torque developed at the shaft of the motor is proportional to the armature current and given by:

$$
K_{t} i=J_{d} \ddot{\theta}_{p}+B_{d} \dot{\theta}_{p}+\operatorname{sgn}\left(\dot{\theta}_{p}\right)\left(T_{d s}+T_{d c}\right)+T_{d l}
$$

The friction torque consists of three terms: static friction, coulomb friction, and viscous damping. Normally, the static friction and coulomb friction of the DC motor are negligible compared to that of the pump swashplate. This is evident by the effortless torque that is required to manually turn only the shaft of the DC motor. 
Neglecting the static and coulomb friction and taking Laplace transforms of equations 1 to 3 yields the model of the DC motor as described by the following transfer function.

$$
\theta_{p}(s)=\frac{K_{t} V(s)-(L s+R) T_{d l}(s)}{s\left((L s+R)\left(J_{d m} s+B_{d m}\right)+K_{t} K_{b}\right)}
$$

The numerator of equation 4 includes two terms. One term is the input signal and the other one is the load, which can be considered as a "disturbance" input signal.

In 1987, Kavanagh [4] developed a comprehensive model for a variable displacement axial piston pump which is used as the basis for modeling the pump in this study. The pump model consisted of the torque model and fluid flow model. The motion of the swashplate is described by the torque model; and the flow rate of the pump is described by the flow model.

Some general assumptions are made regarding the pump model. They are:

- Constant prime drive speed on the pump,

- Zero suction and drain pressure,

- Constant chamber volume

- Constant fluid density and temperature.

In Kavanagh's study, the swashplate is controlled by a control piston and balanced by a return spring. However, in this study, the swashplate is actuated by a DC motor. Under these conditions, Kavanagh's model can be simplified to yield

$$
J_{p} \ddot{\theta}_{p}=T_{d}-S_{1}-S_{2} \theta_{p}-\operatorname{sgn}\left(\dot{\theta}_{p}\right) T_{f c}-B_{p} \dot{\theta}_{p}-K_{p 1} P_{p}-K_{p 2} P_{p} \theta_{p}
$$

The displacement of the pump is defined as follows:

$D_{p}=N A_{p} R_{P} \tan \theta_{p} / \pi$

Assuming that the rotational speed of the prime mover is $\omega_{p}$, the ideal flow rate of the pump is as follows:

$Q_{\text {pidea }}=\omega_{p} D_{p}=\omega_{p} N A_{p} R_{p} \tan \theta_{p} / \pi$

The actual flow rate of the pump is less than the ideal flow rate due to the fluid leakage and fluid compression. There are two types of leakage flows in the pump, one is the internal leakage flow between the suction port and the discharge port of the pump and the other is the external leakage from the high-pressure chamber to the case drain through the pump casing. From the continuity equation, the flow equation of the pump can be written as

$Q_{\text {pidea }}-Q_{i p}-Q_{e p}-Q_{p}=\frac{V_{p}}{\beta_{e}} \frac{d P_{p}}{d t}$

Since the suction pressure is assumed to be zero, the leakage flow of the pump (including the internal leakage and the external leakage flow) can be approximated by

$Q_{l p}=Q_{i p}+Q_{e p}=C_{t p} P_{p}$

Substituting equations.7 and 9 into equation.8, yields

$\omega_{p} N A_{p} R_{p} \tan \theta_{p} / \pi-C_{t p} P_{p}-Q_{p}=\frac{V_{p}}{\beta_{e}} \frac{d P_{p}}{d t}$

As shown in Fig.4, there is a two-stage relief valve (RV), worked as a constant "resistive" load. It is used to adjust the backpressure on the system. 


\section{CLOSED LOOP CONTROL SYSTEM}

The feedback signal is the angular position of the pump swashplate, which is also the controlled variable. The closed loop system is including a controller, a power amplifier, a DC motor and a variable displacement pump. The purpose for controlling the swashplate angle is to control the flow rate of the pump. Before designing the controller, it is important to determine the dynamic performance of the DC motor and pump swashplate assembly. As a result, a model of the DC motor and pump is attempted. Based on this model, a motor controller is designed based on ZieglerNichols turning PID rules, [11]. A typical PID controller has the following transfer function form,

$$
G_{c}(s)=K_{p}+\frac{K_{I}}{s}+K_{d} s
$$

As the system gains changed with pressure changes, the critical gain and oscillation frequency are not the same under different loading. It is interesting to note that at the same pressure level, the pump operation tended to be stabilized by decreasing the gain and destabilized by increasing the gain. On the other hand, at the same gain, the pump tends to be stable with increasing the pressure and unstable with decreasing the pressure. Thus, the pump demonstrates a highly nonlinear characteristic which is strongly dependent on the operating pressure and controller gains, [12].

So at every operating point a new PID gains setting is needed. However, the linear PID is difficult to apply to this highly nonlinear plant. Even with a perfect feedforward controller, a feedback controller is also required to correct for noise and unmeasured disturbances.

The requirement for the controller design at this stage is to design a DC motor controller which could drive the DC motor and pump swashplate at any pressure levels with a fast dynamic response but without exhibiting any limit cycle oscillations.

Many methods can be used to design the controller for a dynamic system; however, most of them are limited to linear systems. As a proposed solution, a NN controller is designed using the linear PID as a teacher to it to control the system at any pressure level.

However, NN is often called a black box, since, unlike fuzzy logic, it is difficult to interpret the knowledge stored by a NN. Knowledge in a NN is represented in the values of the weights and biases, which forms part of large and distributed network.

\subsection{Back-Propagation Algorithm}

Back-propagation learning is one of the most popular types NN learning methods. It has two operational phases. In first phase, forwarding phase, we send input data from input layer to the output layer. In the second phase, back-propagation phase, we calculate the error (between target and output) and propagate the error backwardly to the input layer in order to change the weights of hidden layers by using the gradient descent method.

The neural network is trained, using supervised learning, to develop an inverse model of the plant is shown in Fig.5, the network input is the process output and the network output is the corresponding process input. Inverse model are typically 
developed with steady state data and used for solve the problem of finding the swashplate angle which will produce the required flow rate whatever the pressure level.

Several studies have found that a three-layered neural network with one hidden layer can approximate any nonlinear function to any desired accuracy [13]. The network consists of input layer, hidden layer and output layer. To explain the Backpropagation rule in detail a 3 layer network shown in Fig.6 will be used. The training phase is divided as follows:

1. forward-propagation phase: $X=\left[Q_{p} ; P_{P}\right]$ is propagating from the input layer to the output layer $Y=\left[\theta_{p}\right]$.

$$
\begin{aligned}
& Z_{q}=f\left(\sum_{j=1}^{m} v_{q i} X_{j}\right) \\
& Y_{i}=f\left(\sum_{q=1}^{l} w_{i q} Z_{q}\right)
\end{aligned}
$$

2. back-propagation phase:(14) shows the error between the output, y, and the target, $d$.

$$
E=\frac{1}{2} \sum_{i=1}^{n}\left(d_{i}-y_{i}\right)^{2}
$$

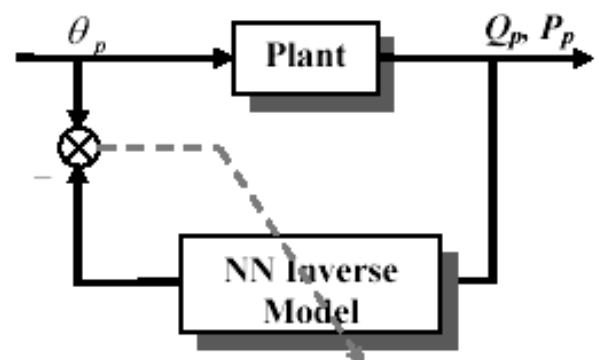

Fig.5 NN plant inverse model

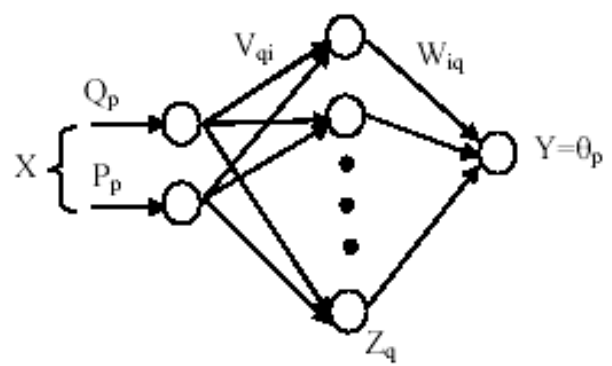

Fig.6 NN for Back-propagation learning

By using the gradient-descent method, the weights in hidden-to-output connections are updated as follows:

$$
\begin{aligned}
\Delta w_{i q}= & -\eta \frac{\partial E}{\partial W_{i q}}=-\eta\left[\frac{\partial E}{\partial Y_{i}}\right]\left[\frac{\partial Y_{i}}{\partial \text { net }_{i}}\right]\left[\frac{\partial \text { net }_{i}}{\partial W_{i q}}\right] \\
& =-\eta\left[d_{i}-y_{i}\right]\left[f^{\prime}\left(\text { net }_{i}\right)\right]\left[Z_{q}\right]=\eta \delta_{o i} Z_{q}
\end{aligned}
$$

Following equations are the weight update on the input-to-hidden correction. Also chain rule and gradient-descent method are employed.

$$
\begin{aligned}
\Delta v_{q i}= & -\eta \frac{\partial E}{\partial V_{q i}}=-\eta\left[\frac{\partial E}{\partial \text { net }_{q}} \|\left[\frac{\partial \text { net }_{q}}{\partial V_{q} j}\right]\right. \\
& =\eta \delta_{h q} x_{i} \\
\delta_{o i} & =-\left[d_{i}-y_{i}\right]\left[f^{\prime}\left(\text { net }_{i}\right)\right] \\
\delta_{h q}= & {\left[\frac{\partial E}{\partial Z_{q}}\right]\left[\frac{\partial Z_{q}}{\partial n e t_{q}}\right] }
\end{aligned}
$$


In Back-propagation learning rule, the two phases are iterated until the performance error decreased to certain small range.

The proposed network consists of the three layers; the output layer consists of one neuron with linear activation function as shown in equation 19 and Fig.7.a. Numbers of neurons in the hidden layer are chosen by trial and error. We begin by five neurons but the network performance is not satisfactory. So, we increased the number to 20 neurons and the performance is improved. Increasing the number may enhance the performance, but we must bear in mind that the smaller numbers is the better in terms of both memory and time requirement to implement the NN. The activation functions in hidden layer neurons are tan sigmoid functions which are defined in equation 20 and shown in Fig.7.b.

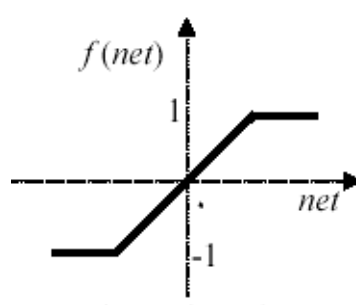

(a) Piecewise Linear

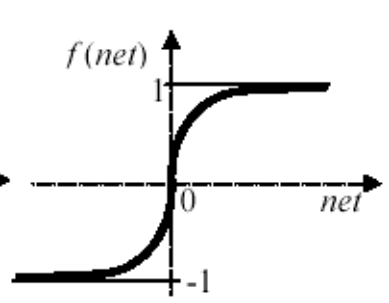

(b) Sigmoid

Fig.7 Activation functions

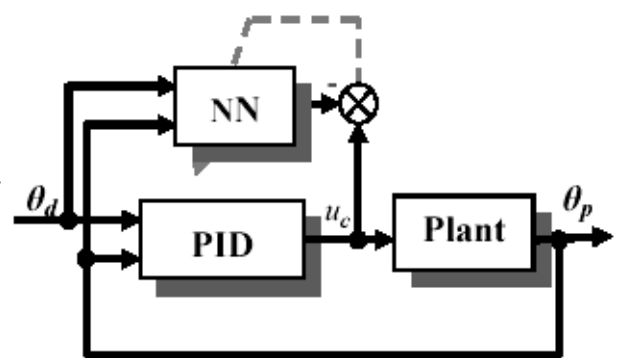

Fig.8 Training a NN to model an existing PID controller

I) piecewise linear activation function

$f($ net $)= \begin{cases}-1 & \text { net }<-1 \\ \text { net } & \mid \text { net } \mid \leq 1 \\ +1 & \text { net }>1\end{cases}$

II) Tan Sigmoid activation function

$f($ net $)=\frac{1-e^{-2 n e t}}{1+e^{-2 n e t}}$

Neural network can be trained to model existing controllers, a straightforward application of supervised learning. The neural network receives the same inputs as the existing controller, and the error between the neural network output and the existing controller output is back-propagated to train the neural network as shown in Fig.8.

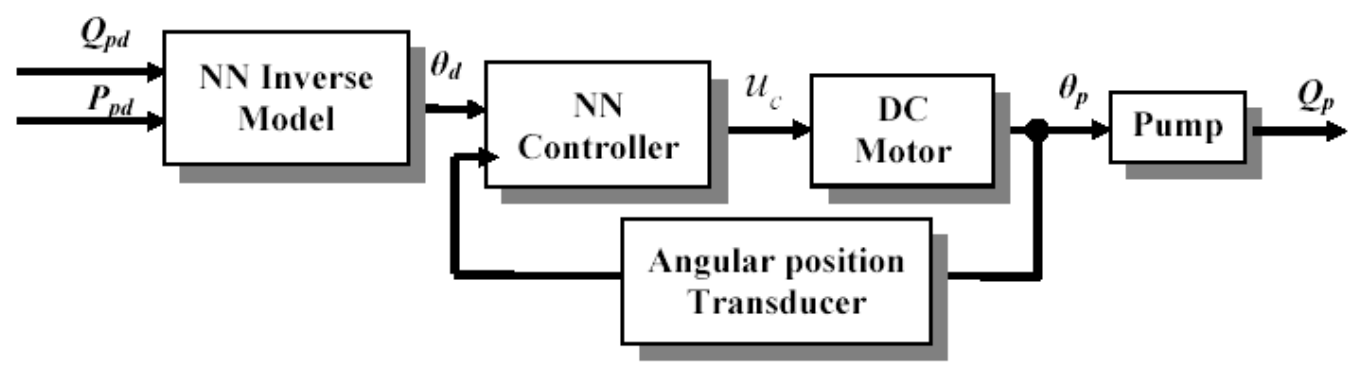

Fig.9 The NN pump control system with the NN inverse model 
A neural network is trained off line using the previous back-propagation learning rule to mimic an existing PID controller and then is further refined in conjunction with a process model. This work is one of the major commercial successes of neurocontrol. Figure 9 illustrates how the proposed controller is trained and implemented.

\section{RESULTS AND DISSECTION}

The proposed NN is used to identify the inverse of system (D-C motor, amplifier, transducers, pump and load) dynamics, then we used this inverse model to generate the input voltage of reference swashplate angle to follow a pre-selected set point in flow and pressure.

The capability of $\mathrm{NN}$ is trained by applying different set points of pump flow rates and pressures. Fig. 10 presents the space relation of the swashplate, pump flow rate and pump pressure. As the swashplate angle is increased the flow rate is increased at the same pressure level. If the back pressure level increases it will has opposite effect in flow rate at the same swashplate set point. The resulted figure will be the base for training the inverse $\mathrm{NN}$ model. It is clear from noticing the three dimensional plot that the relation is nonlinear. Fig.11 shows the target swashplate angle and the trained $\mathrm{NN}$ output angle at different flow rates and pressure levels. The error signal is illustrated in

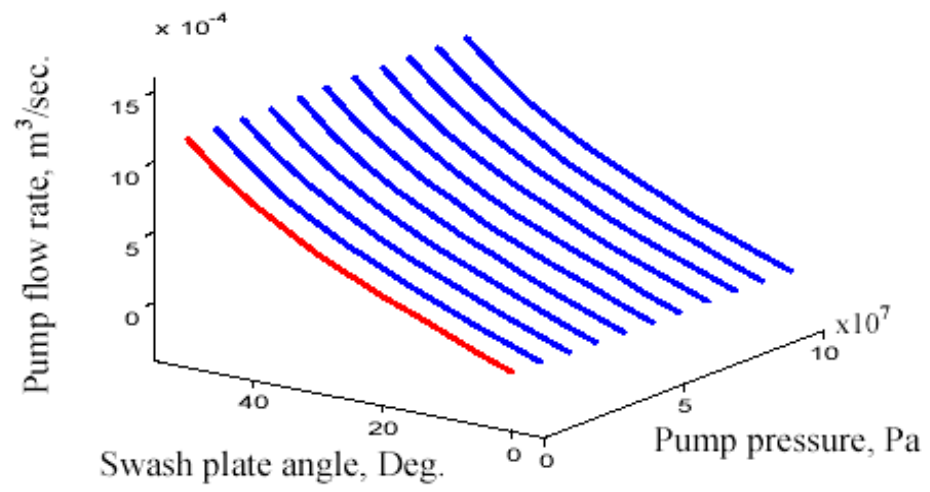

Fig. 10 The training trajectory reference for the inverse NN model

Fig.12. It can be seen from the figure that the trained signal follows the desired signal very closely and the error nearly approach zero $\left(4 \times 10^{-8} \mathrm{~m}^{3} / \mathrm{sec}\right.$.) after 40 samples.

By using Ziegler-Nichols method the PID gains $K p, K_{I}$, and $K_{d}$ will be [2100 $\left.1.9091 \times 10^{5} 5.775\right]$, and it will produce an overshoot response of the swashplate and consequently of the pump flow rate as displayed in Fig.13 and 14. As overshoot of the pump flow rate increases, the overshoot of the hydraulic motor output and the dynamic load also will increase. So the PID control need to improve its gains setting to give minimum overshoots as possible. The trail and error technique is considered to adjust manually the PID gains to get the accepted response of the pump flow rate. 


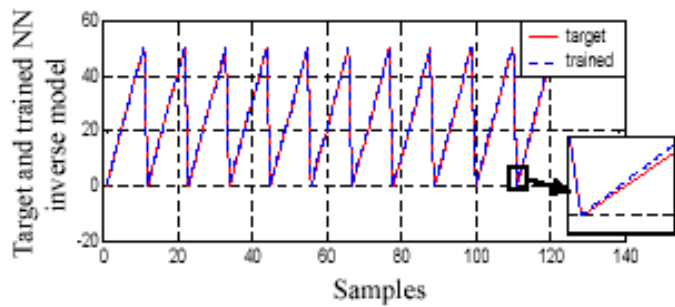

Fig.11. Original and trained responses of the system inverse model

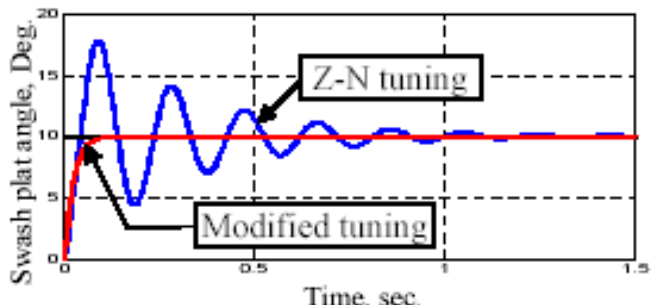

Fig.13 The swashplate angle with reference 10 Deg. based on PID control action

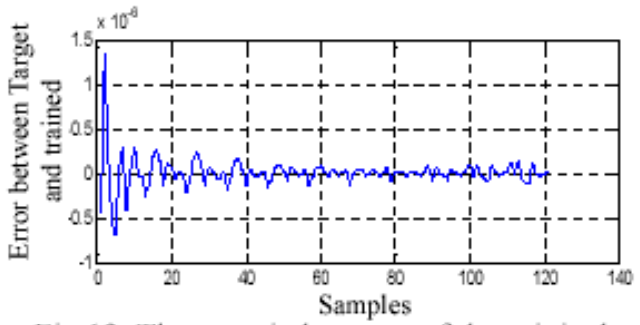

Fig. 12. The error in between of the original and trained responses

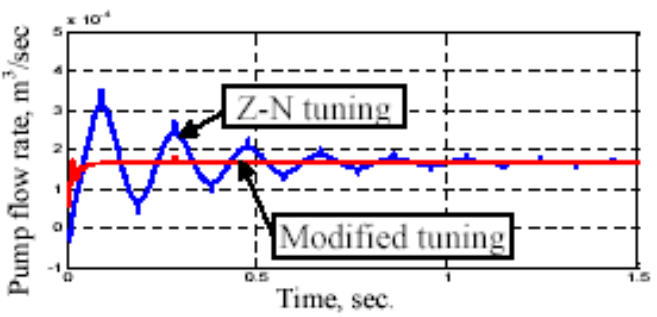

Fig. 14 The pump flow rate based on PID control action

The NN controller voltage will use the modified PID controller as a teacher to it as introduced in Fig.15. The trained signal follows the target signal very closely. For testing the trained $\mathrm{NN}$ controller, a reference swashplate desired trajectory is applied in Fig.16. It is illustrated that the error in between of them is 0.07 Deg at steady state. with rise time of $0.1 \mathrm{sec}$. and no overshoot achieved.

The corresponding response of the modified PID gains $\mathrm{Kp}, \mathrm{K}_{\mathrm{I}}$, and $\mathrm{K}_{\mathrm{d}}$ of [900 56 0.25], is shown in Fig. 17 for the pump flow rate and pressure set point of $\left[1.5 \times 10^{-4}\right.$ $\mathrm{m}^{3} / \mathrm{sec}$., $15 \mathrm{MPa}$ ], it is noticed that the flow rate get steady state error as pressure is increased to $25 \mathrm{MPa}$ or $35 \mathrm{MPa}$. This is reasonable result for the fact of that the controller has not a pressure compensator for these disturbance to the nominal plant. The controller signal at the lower part of Fig.17 does not respond to the changes of the pressure levels. In Fig. 18, the system response based on the proposal trained NN controller has a robustness behavior because of at every pressure level the inverse model repeat the calculation of the adequate swashplate angle to keep the flow rate constant regardless to the pressure level.

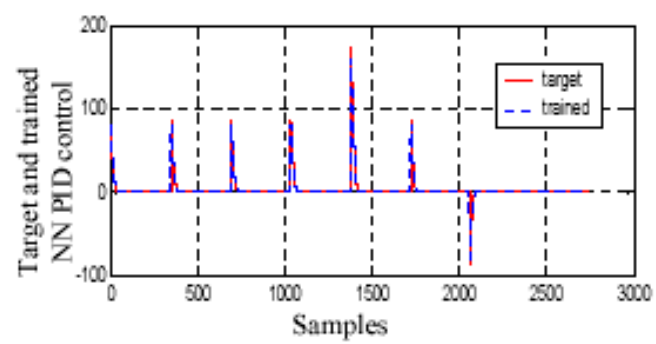

Fig.15. Original and trained signals of the PID control action and the error in between

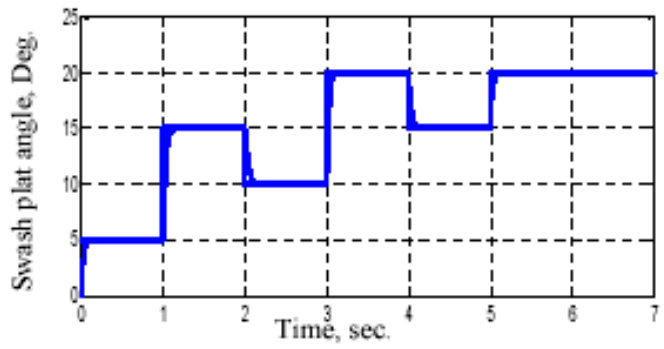

Fig.16 The swashplate angle response based on $\mathrm{NN}$ controller. 

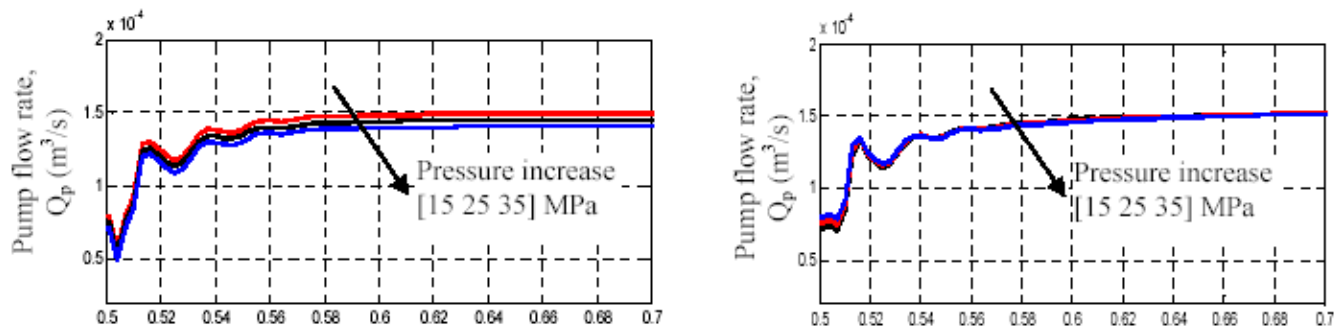

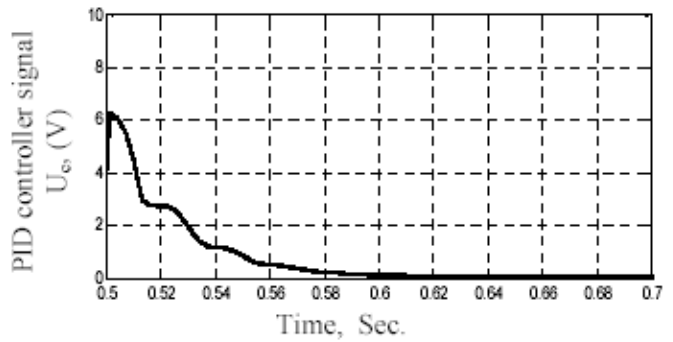

Fig.17 The system flow rates based on modified PID control action and the controller signal with different pressure levels

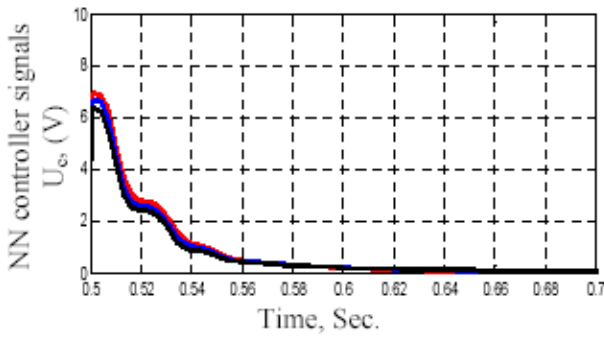

Fig.18 The system flow rates based on NN control action and the controller signals with different pressure levels

To improve the dynamic response of the pump, a DC motor is implemented to control the pump swashplate (and hence flow rate) directly. The pump and DC motor are mathematically modeled and their parameters are simulated via MATLAB 6.3 and SIMULINK 5.0 software. By means of the DC motor's quick dynamic response, the DC motor controlled pump demonstrated a fast dynamic response independent on the pump pressure.

For precise control, an off-line learning algorithm is introduced. The strategy of design is also given. It is important to note that the $\mathrm{NN}$ have the distinct advantage of not relying on the system parameters and it deal with system as a black box. The simulation results indicate the accuracy of tracking. Also the effectively of the proposed controller with the inverse $\mathrm{NN}$ model is cleared. It gave a robustness response, as the pressure changes, the pump does not affect to a great extent the output flow rate accuracy.

\section{REFERENCE}

[1] Merritt, H., 1967, "Hydraulic Control Systems", John Wiley \& Sons, Inc., New York, pp.152-157.

[2] "HT-High Torque, Direct Drive Series", Emoteq Inc., Tulsa, Oklahoma

[3] Tonglin Shang, 2004, "Improving Performance of an Energy Efficient Hydraulic Circuit", MSc. University of Saskatchewan, Saskatoon, Saskatchewan, Canada.

[4] Kavanagh, G. P., 1987, "The Dynamic Modelling of an Axial Piston Hydraulic Pump", MSc Thesis, Department of Mechanical Engineering, University of Saskatchewan, Canada. 
[5] Zeiger, g and Akers, A., 1986,"Dynamics Analysis of an Axial Piston Pump Swashplate Control", proceeding of Instaan. Mech. Engrs part C, pp.49-58.

[6] Wahid, A. El-Sayed, and Yehia. El-Mashad, May 2002, "Fuzzy Control of Highly Sensitive Dynamics Behaviours of Variable Displacement Axial Piston Pump", proceeding of the $10^{\text {th }}$ Int. AMME conference, Egypt.

[7] G.S. Virk and A. Al-Dmour, Jan.1994 "System Simulation Using Neural Networks", Departmental Research Report No. 537, University of Bradford.

[8] J. Jantzen, 30 Oct 1998, "Neurofuzzy Modelling", Bldg 326, DK-2800 Lyngby, DENMARK Tech. report no 98-H-874 (nfmod).

[9] D. Nauck and R. Kruse, 1999, "Neuro-Fuzzy Systems for Function Approximation", Fuzzy Sets and Systems (101)2 pp. 261-271.

[10] Habibi, S., 2001, "Lecture Notes: Control System I", Department of Mechanical Engineering, University of Saskatchewan, Canada.

[11] Ziegler, J. G. and N. B. Nichols, 1942, "Optimum Settings for Automatic Controllers", ASME Trans. 64 (1942), pp. 759-68.

[12] You, Z., 1993, "Sliding Mode Control of A Variable Displacement Hydraulic Pump", PhD. Thesis, University of Saskatchewan, Saskatoon, Canada.

[13] R.J. Schalkoff, 1997, “Artificial Neural Networks”, McGraw-Hill, Inc.

\section{التحكم فى تدفقي مضخَّة مكبسيه ذات إزاحةِ متغيرّةِ مع تعويضِ الضغطِ بإستعمال الثبكة العصبية}

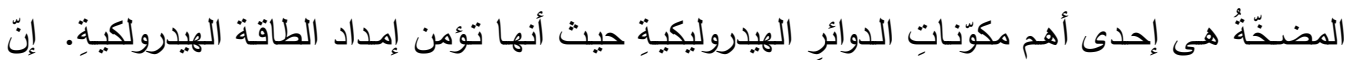

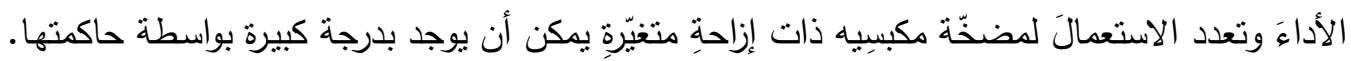

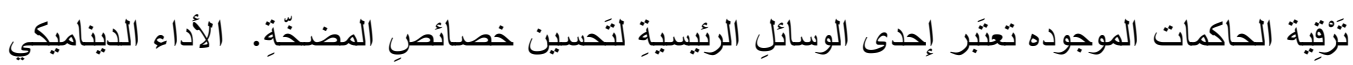

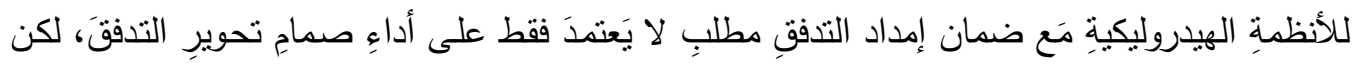

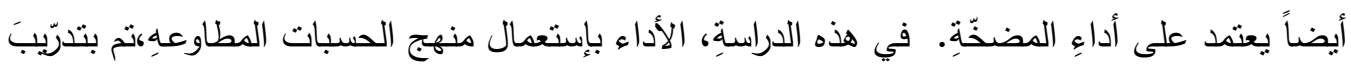

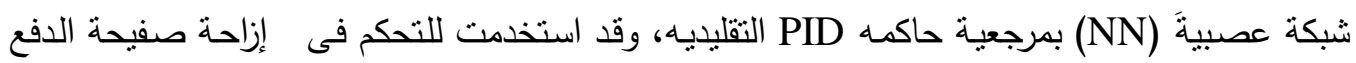

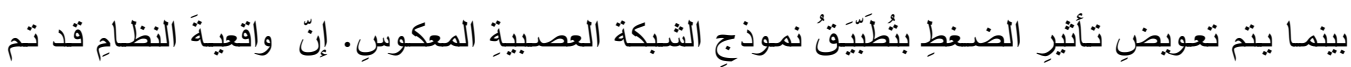
مماتلتها وكذلك تأسيس موضوع التطبيقِ لنظام التحكم لهذه الطلمبات. وأنـه يُرى أنّ إستعمالَ الطريقه

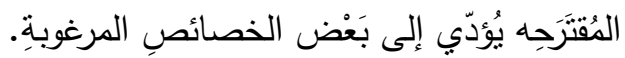

